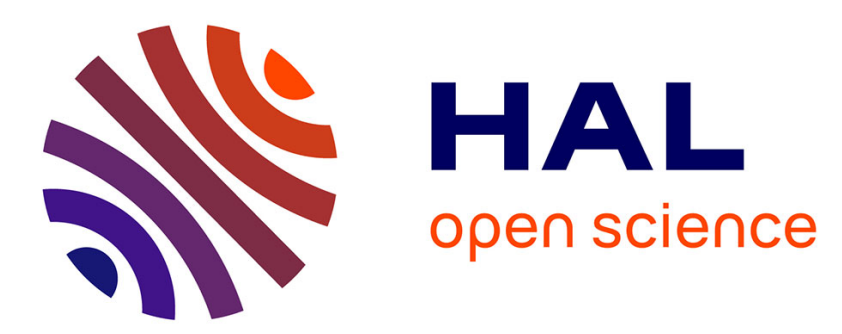

\title{
Characterisation of aluminium diffusion coatings elaborated on austenitic stainless steels and on ferritic-martensitic steels
}

Claire C. Boulesteix, Fernando Pedraza

\section{- To cite this version:}

Claire C. Boulesteix, Fernando Pedraza. Characterisation of aluminium diffusion coatings elaborated on austenitic stainless steels and on ferritic-martensitic steels. Surface and Coatings Technology, 2018, 339, pp.27-36. 10.1016/j.surfcoat.2018.01.086 . hal-02467115

\section{HAL Id: hal-02467115 https://hal.science/hal-02467115}

Submitted on 4 Feb 2020

HAL is a multi-disciplinary open access archive for the deposit and dissemination of scientific research documents, whether they are published or not. The documents may come from teaching and research institutions in France or abroad, or from public or private research centers.
L'archive ouverte pluridisciplinaire HAL, est destinée au dépôt et à la diffusion de documents scientifiques de niveau recherche, publiés ou non, émanant des établissements d'enseignement et de recherche français ou étrangers, des laboratoires publics ou privés. 


\title{
Characterisation of Aluminium Diffusion Coatings Elaborated on Austenitic Stainless Steels and on Ferritic-Martensitic Steels
}

\author{
Claire Boulesteix, Fernando Pedraza \\ Laboratoire des Sciences de l'Ingénieur pour l'Environnement (LaSIE, UMR-CNRS 7356), \\ Université de La Rochelle, Avenue Michel Crépeau, 17042 La Rochelle Cedex 1, France \\ claire.boulesteix@univ-lr.fr ;fernando.pedraza@univ-lr.fr
}

\begin{abstract}
Slurry aluminide coatings were elaborated on IN-800HT and HR3C austenitic stainless steels (ASS) and on P92 ferritic-martensitic steels. The thermal treatments conducted in Ar enabled the melting of $\mathrm{Al}$ and the high temperature synthesis with the substrate elements to result in an aluminium diffusion coating. Whether for the ferritic-martensitic or the austenitic stainless steels, the coatings were formed by the simultaneous $\mathrm{Al}$ inward diffusion into the steel matrix and the outward diffusion of Fe (and Ni for the ASS) on both steel substrates. As a result, the coatings exhibited a $\mathrm{B} 2-(\mathrm{Fe}, \mathrm{Ni}) \mathrm{Al}$ phase for the ASS and $\mathrm{B} 2-\mathrm{FeAl}$ phase for the P92 substrate. A reduction of the grain size after annealing was noticed for the ASS but their microstructures remained mostly austenitic. However, a significant increase of the grain size occurred in the P92 steel with a transformation from the initial tempered martensitic structure to an austenitic structure. The microhardness of the ASS did not change significantly whereas for P92, a large increase occurred.
\end{abstract}

Keywords: Austenitic steels, Ferritic-martensitic steels, Aluminium diffusion coatings, Characterisation.

\section{INTRODUCTION}

In order to achieve higher efficiencies and to decrease the $\mathrm{CO}_{2}$ emissions in the power generation industry, the operating temperatures and pressures have to be increased $[1,2]$. The new generation of ultra-supercritical power plants (USC units) operate with steam temperatures up to $600-650^{\circ} \mathrm{C}$ and pressures from 25 to $30 \mathrm{MPa}[3,4]$. In these plants, austenitic stainless steels are commonly employed in superheaters and reheaters of steam boilers whereas ferritic martensitic steels are preferred for larger components like tubes and pipes [5-7]. Due to their high temperature oxidation and corrosion resistance combined with their high strength, the HR3C and the IN-800HT austenitic stainless steels (ASS) can be employed in USC units [8, 9]. With a density of $8 \mathrm{mg} / \mathrm{cm}^{2}$, IN-800HT is a modified version of IN-800 containing more Ni, 
$\mathrm{Si}, \mathrm{Mn}$ and $\mathrm{Ti}[10,11]$. This material is well-known to resist to stress corrosion and like for the HR3C steel, the presence of chromium in these alloys allows the formation of a protective oxide layer while the presence of nickel improves the stability of the oxide formed $[8,10,12]$. The nitrogen in the interstitial sites of the matrix contained in the HR3C alloy combined with $0.4 \mathrm{Nb}$, $25 \mathrm{Cr}$ and $20 \mathrm{Ni}$ (wt\%) additions represent an effective measure of the enhancement of creep strength $[8,13]$. The P92 ferritic martensitic alloy is one of the most commonly employed high $\mathrm{Cr}$ creep resistant steels in large components of USC units because of its high creep rupture strength, its excellent mechanical properties, its good weldability, its low thermal expansion, its high thermal conductivity and its adequate corrosion resistance [8, 14-17]. However, despite the good properties of these three alloys, they need to be coated in order to enhance their lifetime at higher temperatures and pressures. In severe atmospheres encountered in USC units, $\mathrm{SiO}_{2}$ can dissolve and $\mathrm{Cr}_{2} \mathrm{O}_{3}$ can form volatile $\mathrm{Cr}$ oxy-hydroxyl species $[18,19]$. Thus, $\mathrm{Al}_{2} \mathrm{O}_{3}$ is the only oxide ensuring the lifetime increase of the components. This external protective $\mathrm{Al}_{2} \mathrm{O}_{3}$ scale can grow from Al diffusion coatings [20]. In particular, slurry aluminising offers the possibility of coating large components [21] and is considered as low cost and easy-to-apply process [22]. Slurry coatings can be applied to a metallic substrate by brushing, spraying or by dip-coating [23]. Slurries are suspensions of aluminium micro-particles on a binder-solvent system [22]. In our case, the solvent is water, thus making our coatings environmentally friendly [24]. Once the Al slurry has been sprayed, the subsequent thermal treatment pyrolyses the binder and makes the molten aluminium to react with the substrate to form an aluminide intermetallic phase $[21,23,25]$. These coatings have shown their excellent resistance even after 2000 hours in steam at 650 or $700^{\circ} \mathrm{C}$, for respectively P92 and IN-800HT and for the HR3C alloy [25-27]. Experiments conducted by Agüero et al. have shown the good behaviour of another kind of aluminium slurry deposited on P92 ferritic-martensitic steels for 41000 hours in steam, at $650^{\circ} \mathrm{C}$ [28]. In addition, they can be repaired [29] and the potential cracks can be sealed [30]. However, although the high temperature behaviour of these aluminides has been discussed, there is no real description of the slurry coatings themselves in the open literature, let alone in what the aluminising treatment may affect the microstructure and microhardness of the parent material, which are the main aims of this work.

\section{EXPERIMENTAL PROCEDURE}

\section{1 - Materials of Study}


IN-800HT coupons of $16 \mathrm{~mm}$ diameter and $2 \mathrm{~mm}$ thick were ground with SiC\#180 paper. The same procedure was conducted with HR3C and P92 coupons of $20 * 10 * 2 \mathrm{~mm}$. The nominal compositions of the three studied substrates are given in Table 1.

TABLE 1. Nominal and experimental (EDS) compositions of IN-800HT, HR3C and P92 substrates $(\mathrm{wt} \%)$.

\begin{tabular}{|c|c|c|c|c|c|c|c|c|}
\hline & & $\mathbf{F e}$ & $\mathbf{N i}$ & $\mathrm{Cr}$ & $\mathrm{C}$ & $\mathbf{T i}$ & $\mathbf{S}$ & Others \\
\hline \multirow[t]{2}{*}{ IN-800HT } & Nominal & Bal & $30-35$ & $19-23$ & $0.10 \max$ & $0.15-0.60$ & $0.015 \max$ & $\begin{array}{c}\text { Si: } 1 \max \\
\mathrm{Mn}: 1.5 \max \\
\mathrm{Cu}: 0.75 \max \end{array}$ \\
\hline & EDS & 45 & 29 & 21 & $<1$ & $<1$ & - & Si: $1-2$ \\
\hline \multirow[t]{2}{*}{ HR3C } & Nominal & Bal & $17-23$ & $23-27$ & 0.06 & - & - & $\begin{array}{c}\mathrm{Si}: 0.4 \\
\mathrm{Mn}: 1.2 \\
\mathrm{Nb}: 0.20-0.60 \\
\mathrm{~N}: 0.15-0.35\end{array}$ \\
\hline & EDS & 53.5 & 20 & 25 & $<1$ & - & - & $\begin{array}{l}\text { Mo: } 0.4 \\
\text { Nb: } 0.5\end{array}$ \\
\hline \multirow{2}{*}{ P92 } & Nominal & Bal & $0.4 \max$ & $8.50-9.50$ & $0.07-0.13$ & - & $0.01 \max$ & $\begin{array}{c}\text { Si: } 0.50 \\
\text { Mn: } 0.30-0.60 \\
\text { Mo: } 0.30-0.60 \\
\text { W: } 1.5-2 \\
\text { V: } 0.15-0.25\end{array}$ \\
\hline & EDS (wt $\%)$ & 87 & - & 9 & - & - & - & $\begin{array}{c}\text { Mn: }<1 \\
\text { Mo: }<1 \\
\text { W: } 2\end{array}$ \\
\hline
\end{tabular}

Aluminium micro-particles (4-5 $\mu \mathrm{m}$ average size, Hermillon, France) were used to aluminise the substrates. In order to obtain a more precise particles size and their composition, the powders were microscopically analysed. Characterisation of the Al powders and of the slurry were performed by DSC measurements, using a SETARAM Labsys Evo 1600 thermal analysis. The heating and cooling rates of these analyses were $10^{\circ} \mathrm{C} \cdot \mathrm{min}^{-1}$ and the tests were performed under argon $(20 \mathrm{~mL} / \mathrm{min})$. The $\mathrm{Al}$ microparticles were heated up to $1300^{\circ} \mathrm{C}$ and up to $700^{\circ} \mathrm{C}$ for the slurry since after the melting of Al no significant event is recorded for the slurry [31].

\section{2 - Aluminisation}

All the samples were coated by spraying aluminium slurry containing $43 \mathrm{wt} \% \mathrm{Al}$ micro-particles dispersed in $57 \mathrm{wt} \%$ of binder (1/10 polyvynil alcohol/deionized water). After drying in ambient air for at least 1 hour [31], the coated samples were annealed in $\operatorname{argon}\left(400^{\circ} \mathrm{C} / 3 \mathrm{~h}+650^{\circ} \mathrm{C} / 3 \mathrm{~h}+\right.$ $1000^{\circ} \mathrm{C} / 1 \mathrm{~h}$ or $1100^{\circ} \mathrm{C} / 1 \mathrm{~h}$ for, respectively the ferritic-martensitic steel and the austenitic stainless steels). These coating conditions were based in previous investigations on nickel- 
based superalloys $[23,32]$ but were slightly lowered in temperature and shortened in time for these Fe-based alloys.

\section{3 - Vickers microhardness and evalution of the grain size}

Microhardness values were measured across the additive layer and the interdiffusion zone of the coatings and in the substrate for each coated material. The acquisitions were performed using a Shimadzu Type M tester with a Vickers indenter, with a load of $15 \mathrm{~g}$ and for 10 seconds. The average values of microhardness were calculated from 10 indentations performed for each part of the coating/substrate system [33].

The average grain sizes of the coatings and of the steel core materials were evaluated using the ASTM E112 standard test method [34]. The intercept procedure was selected and involves an actual count of the number of grain boundary intersections with a test line per unit length of test line. For each system, 6 lines were plotted in 2 spatial dimensions in order to get a better average.

\section{4 - Crystal Structures Before and After Aluminisation}

The crystal structure was determined by X-Ray Diffraction (XRD) using a Bruker AXS D8 Advance $\left(\mathrm{CuK}_{\alpha}\right.$ radiation), in $\theta-2 \theta$ mode.

\section{5 - Etching}

In order to obtain informations about the distribution and the size of the grains, the samples were mounted in resin, polished and etched before microscopic characterisation. The P92 samples were immersed for few seconds in a solution of Nital 5\%. For aluminised IN-800HT, an electrochemical etching was realized by immersion for 3-5 seconds in a $10 \mathrm{vol} \% \mathrm{H}_{2} \mathrm{SO}_{4}$ aqueous solution. For the uncoated IN-800HT and for the uncoated and aluminised HR3C, chemical etching was realized with a Kalling $\mathrm{n}^{\circ} 2$ solution $\left(5 \mathrm{~g} \mathrm{CuCl}_{2}+100 \mathrm{~mL} \mathrm{HCl}+100 \mathrm{~mL}\right.$ ethyl alcohol).

\section{6 - Microscopic Characterisation}

The etched cross-sections of the uncoated/coated samples were analysed using a Leica DMRM microscope and a LEICA MC170HD camera coupled with the software LAS v4.9 for the 
images acquisition. All the samples were also characterised by scanning-electron microscopy (SEM) in a FEI Qanta 200F FEG with an EDAX detector for chemical analyses.

\section{RESULTS}

3. 1-Aluminium particles and corresponding slurry Preliminary analyses were carried out on the $\mathrm{Al}$ micro-particles in order to obtain an average size. Fig. 1. a) highlights the relatively heterogeneous distribution of the particle size. Indeed, some particles can measure up to 12 microns while the smallest ones do not exceed 0.5 microns. The Gaussian plot of Fig. 2. b) shows that average size of the Al particles used in this study is about 3 microns. Oxygen was detected in small quantities $(\approx 5-8$ at $\%$ ) and Ar was also quantified to less than 1 at $\%$, which arise from the wire explosion method employed to produce the particles [35, 36]. In contrast, no other elements were detected. In order to clarify this point, DSC measurements were carried out with the Al micro-particles. The corresponding thermogram shown in Fig. 2. a) let appear an endothermic event at $657 \pm 1^{\circ} \mathrm{C}$ which is below the theoretical melting point of $\mathrm{Al}\left(660.5^{\circ} \mathrm{C}\right.$ [37]). This difference of melting temperature is probably due to the presence of impurities in the powders not highlighted with the EDS analyses [38, 39]. Thereafter, the evolution of the transformation of the slurry was characterised by DSC up to $700^{\circ} \mathrm{C}$, at which full decomposition of the binder and melting of aluminium are achieved [40].
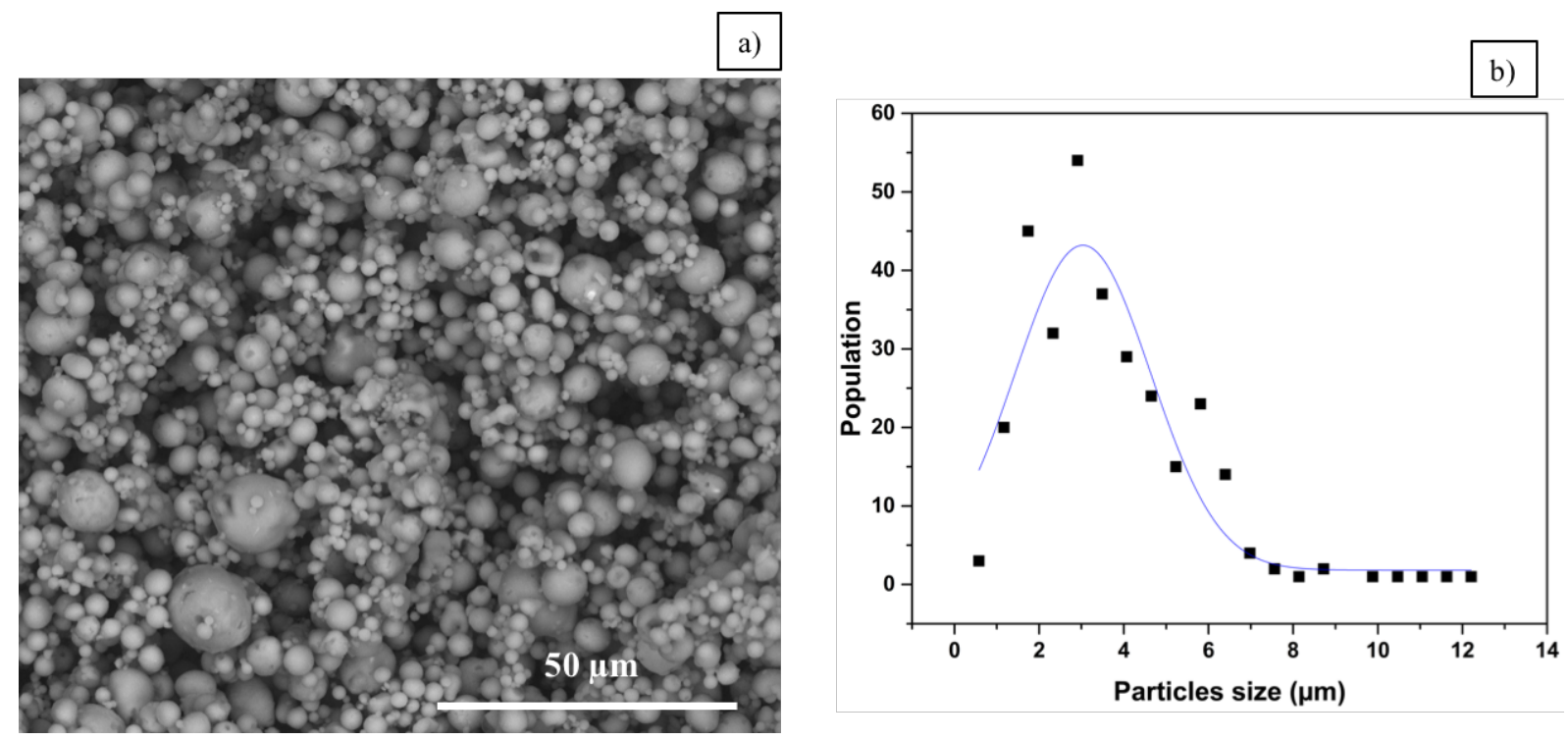

FIGURE 1. Micrographs of Al micro-particles used in this study (a) and their size distribution (b). 
The slurry thermogram shown in Fig. 2. b) reveals four phenomena. The first phenomenon occurs below $100^{\circ} \mathrm{C}$ and was associated with the free water contained in the slurry [31]. The second event taking place at $100^{\circ} \mathrm{C}$ is endothermic and was ascribed to the evaporation of water. The third phenomenon appears between 200 and $300^{\circ} \mathrm{C}$ but is less marked than the previous ones. Rannou et al. ascribed such phenomenon to the PVA, including the free water trapped in the PVA film, its subsequent melting and its final decomposition [31]. A final but important endothermic signal was noticed at $657 \pm 1{ }^{\circ} \mathrm{C}$ similar to the one of Fig. 2. a) for pure Al.
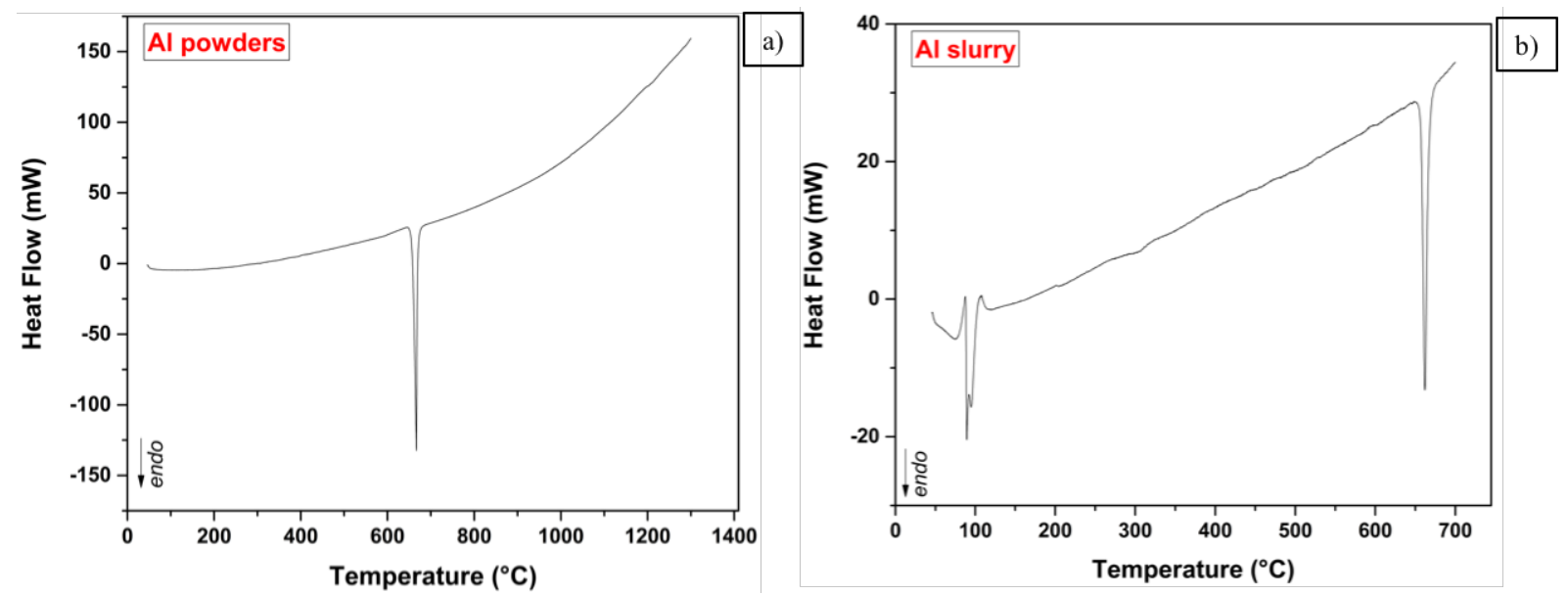

FIGURE 2. DSC curves upon heating $\left(10^{\circ} . \mathrm{min}-1\right)$ under $\operatorname{Ar}(\mathrm{g})$ flow of (a) the Al microparticles and (b) of the Al slurry.

\section{2 - Aluminide coatings}

As shown in Fig. 3, the microstructure and the composition of the coatings appeared very homogeneous in the three steels. 

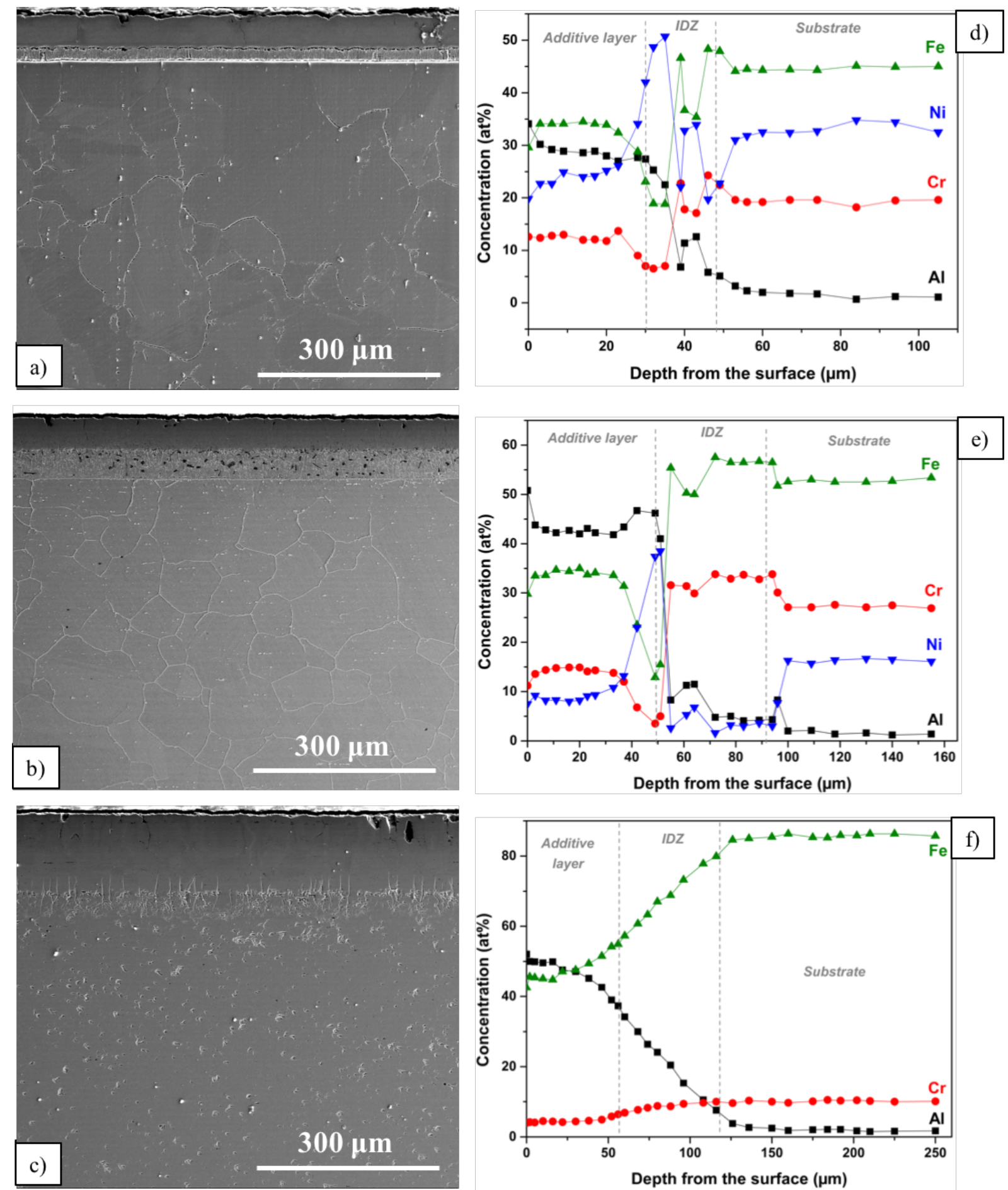

FIGURE 3. SEM cross-sections of aluminised (a) IN-800HT, (b) HR3C, (c) P92 steels and their corresponding EDS profiles (d, e and f, respectively).

The coatings can be divided in two major parts: an outer additive layer and an inner interdiffusion layer. The average composition of the additive layer of the IN-800HT substrate was about $35 \mathrm{Fe}, 30 \mathrm{Al}$ and $25 \mathrm{Ni}$ (wt\%), which corresponds mostly to the B2-(Fe,Ni)Al phase according to the $\mathrm{Fe}-\mathrm{Ni}-\mathrm{Al}$ ternary diagram at $1050^{\circ} \mathrm{C}$ (Fig. 4. a) [41]. In the $\mathrm{HR} 3 \mathrm{C}$ steel, the 
additive layer contained more $\mathrm{Al}(45 \mathrm{wt} \%$ ) than in the IN-800HT (30 wt \%), the Fe content was similar and the Ni content was two times lower (10 and $20 \mathrm{wt} \%$ for the coated HR3C and IN$800 \mathrm{HT}$ substrates, respectively). Despite these differences, the additive layer of the HR3C also corresponded to the B2 phase, as shown in Fig. 4. a). The XRD analyses carried out on the coated austenitic stainless steels (Fig. 5. a) confirmed this hypothesis with the appearance of the six characteristic peaks of the B2 phase. As shown in Figs. 3. a) and b), the thickness of the additive layer of the coated IN-800HT and HR3C was very similar (about $50 \mu \mathrm{m}$ ). However, the interdiffusion zone of the HR3C specimen appeared 2.5 times thicker than that of IN800HT. The X-ray maps shown in Figs. 6. a) and b) highlight a homogenous distribution of Al in the entire thickness of the additive layers. Nevertheless, a $\mathrm{Cr}$ and Fe depletion was observed close to the interface between the additive and the interdiffusion layers. On the contrary, a $\mathrm{Ni}$ enrichment occurred at the same area.
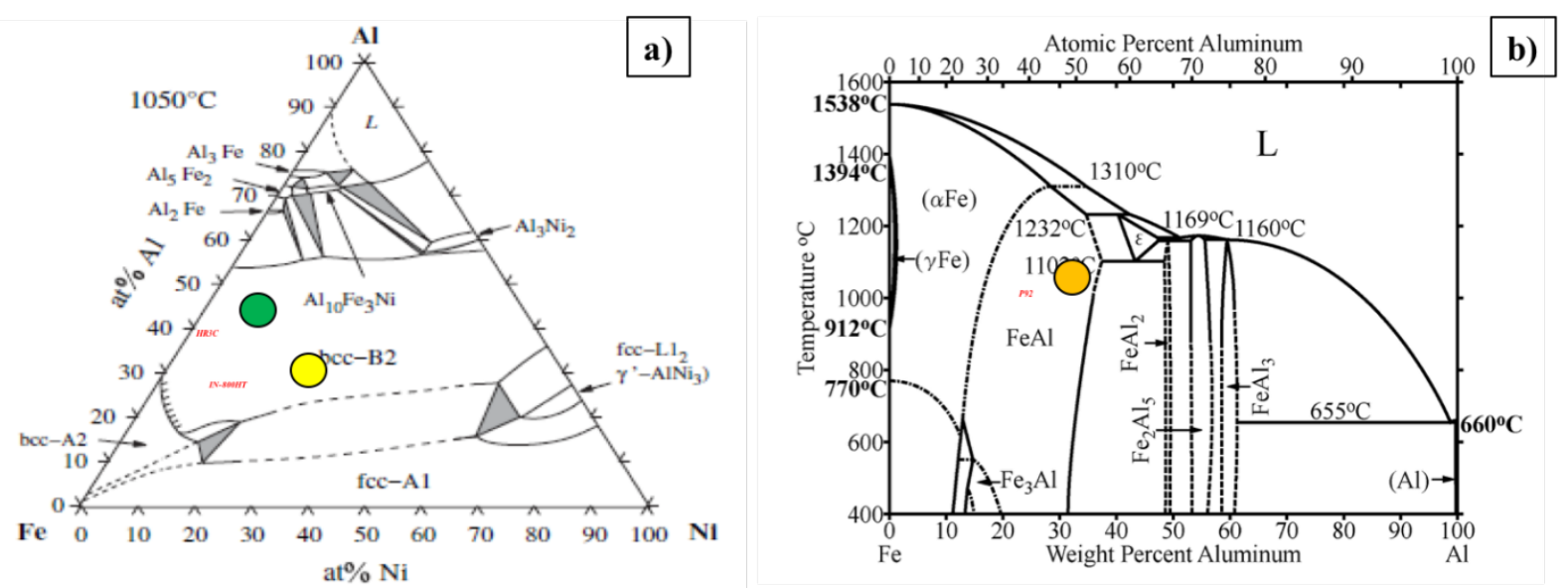

FIGURE 4. (a) Fe-Ni-Al diagram [41] and (b) Fe-Al diagram [42]. Compositions of the additive layer of IN-800HT (yellow circle), HR3C (green circle) and P92 (orange circle). 

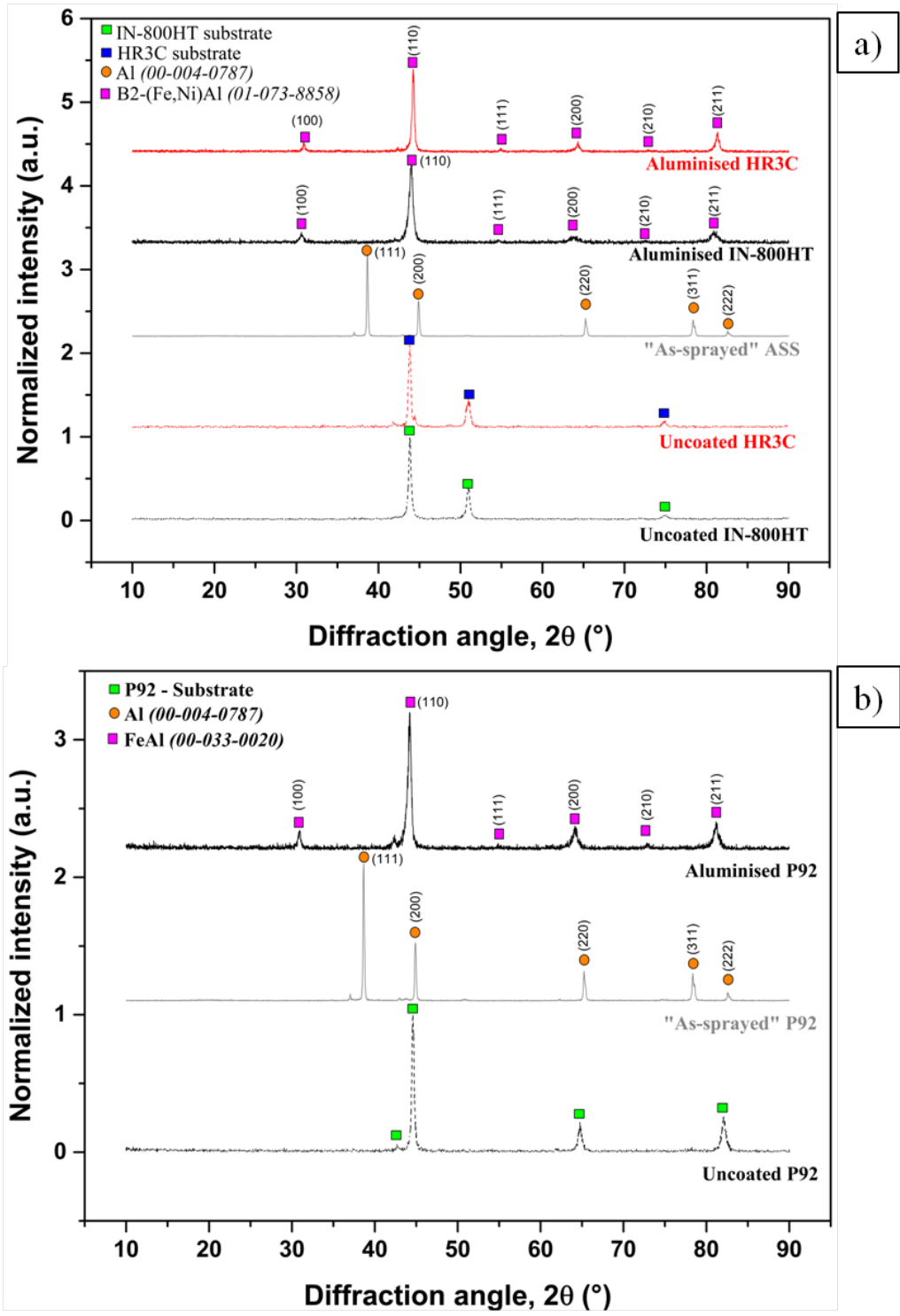

FIGURE 5. X-ray patterns of the (a) IN-800HT and HR3C austenitic stainless steels and (b) of the P92 ferritic-martensitic steel before and after aluminisation. 

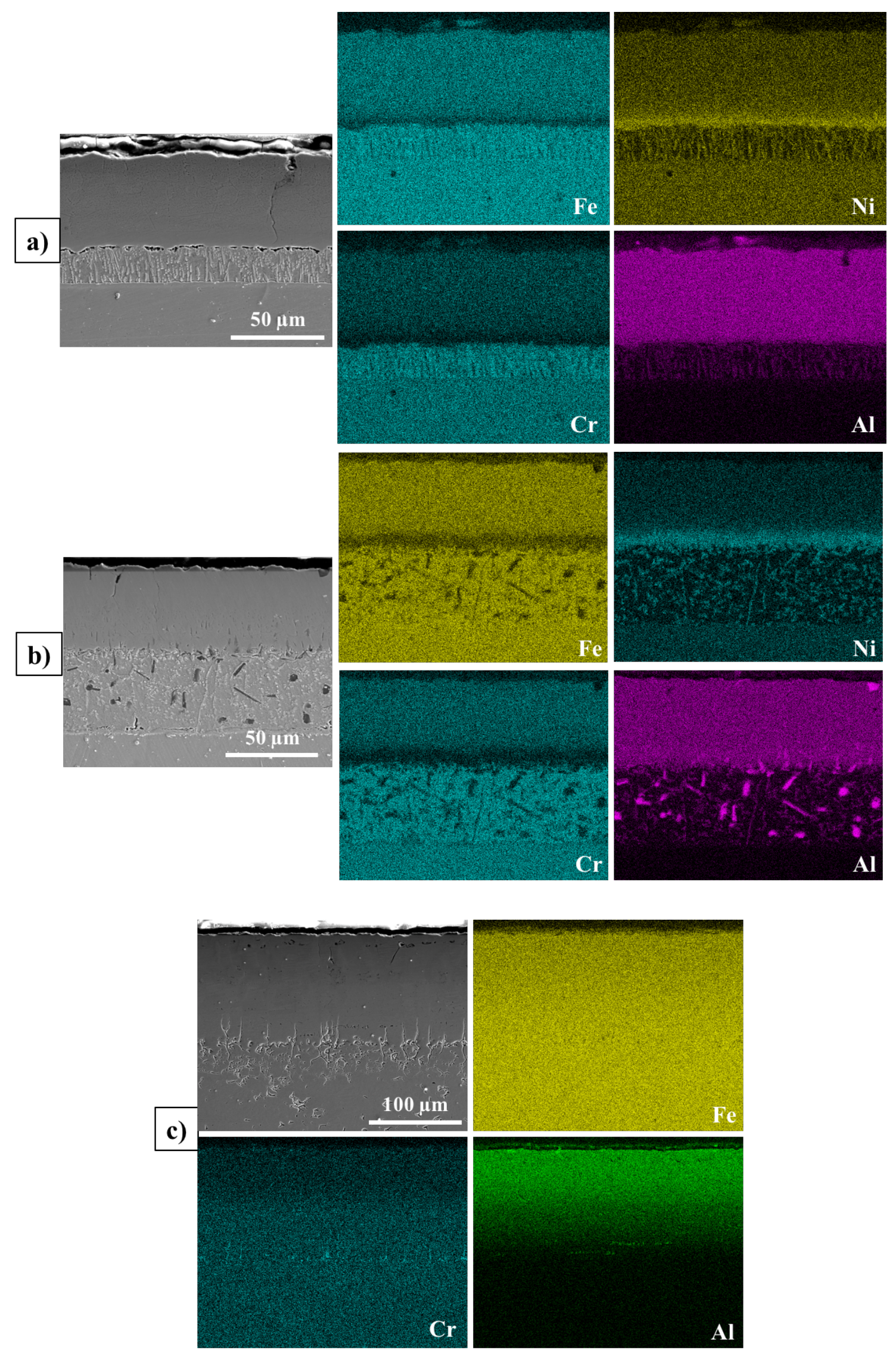

FIGURE 6. X-ray maps of the slurry aluminide coatings on (a) IN-800HT, (b) HR3C and (c) P92 steels. 
For the P92 ferritic-martensitic steel (Fig. 3. c), the additive layer and the interdiffusion zone appeared thicker compared to the ASS. Indeed, the additive layer was about $60 \mu \mathrm{m}$ thick while the thickness of the interdiffusion zone was even greater to reach about $70 \mu \mathrm{m}$. The additive layer was homogeneous and composed by $50 \mathrm{at} \%$ of $\mathrm{Al}$ and 45 at\% Fe which corresponds to the B2-FeAl phase by comparing with the Fe-Al binary diagram (Fig. 4. b) [42]. The XRD analyses carried out on these samples confirmed the existence of the B2 phase (Fig.5 b). The X-ray maps realized on the aluminised P92 ferritic-martensitic steel (Fig. 5. c) shows a good homogeneity of the $\mathrm{Al}$ distribution in the coating and an enrichment of $\mathrm{Cr}$ from the additive layer/interdiffusion interface to the rest of the substrate to reach about 10 at\% (Fig. 3. c).

Despite of a good homogeneity in terms of microstructure, compositions and thicknesses of the coatings, some cracks were detected on austenitic stainless steels. As reported by our group, $[27,29]$ the number of cracks in aluminised HR3C was a little bit greater than in the IN-800HT case due to the most important stiffness of the former [43]. Previous works have linked these cracks to the mismatch between the thermal expansion coefficients of the different metallurgical phases $[28,44,45,46]$. Other authors have reported this phenomenon with tensile stress from the substrate occurring upon heating [47].

\section{3 - Metallurgical evolutions induced by the aluminisation process}

As shown in Figs. 7. a) and a'), the thermal treatment seemed to reduce the grain size of IN$800 \mathrm{HT}$. Indeed the average grain size of the uncoated and the aluminised substrates were, respectively, $219.5 \pm 39.2 \mu \mathrm{m}$ and $134.2 \pm 11.7 \mu \mathrm{m}$ (Table 2). For the HR3C substrate, it appeared that the grain size had slightly increased after aluminising while different carbides were also observed. Some square-like precipitates were found in the bulk of IN-800HT and were associated with TiC [48]. Moreover, some Cr carbides were detected in both steels as well as $\mathrm{Nb}$-rich carbonitrides [13] and also $\mathrm{M}_{23} \mathrm{C}_{6}$ which are typical of the ASS after annealing at high temperatures $[9,13]$. These precipitates were mainly located within the matrix (grains) of the untreated ASS but appeared with a round shape at the grain boundaries and with a cuboidal morphology within the grains after aluminisation [49] as shown in Fig. 7. a') and b'). 

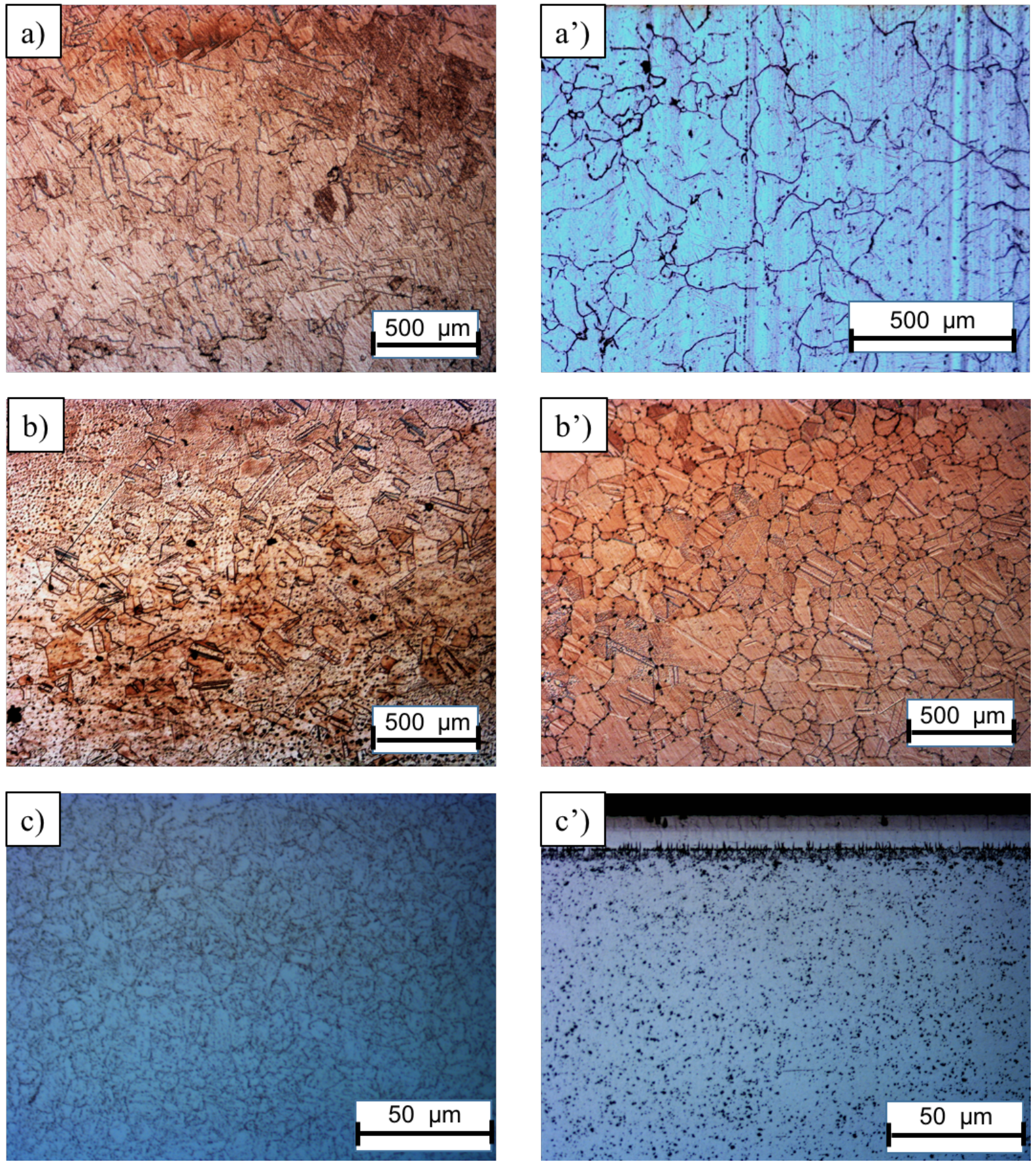

FIGURE 7. Optical micrographs of uncoated (a) IN-800HT (Kalling $n^{\circ} 2$ ), (b) HR3C (Kalling $n^{\circ}$ ), (c) P92 (Nital 5\%) and aluminised (a') IN-800HT (10\% vol $\mathrm{H}_{2} \mathrm{SO}_{4}$ ), (b') HR3C (Kalling $\left.n^{\circ} 2\right)$, (c’) P92 (Nital 5\%).

TABLE 2. Grain sizes of the uncoated and aluminised substrates studied in this work.

\begin{tabular}{|c|c|c|c|c|c|}
\hline \multicolumn{2}{|c|}{ IN-800HT austenitic stainless steel } & \multicolumn{2}{c|}{ HR3C austenitic stainless steel } & \multicolumn{2}{c|}{ P92 ferritic-martensitic steel } \\
\hline Uncoated & Aluminised & Uncoated & Aluminised & Uncoated & Aluminised \\
\hline $219.5 \pm 39.2 \mu \mathrm{m}$ & $134.2 \pm 11.7 \mu \mathrm{m}$ & $78.8 \pm 11.8 \mu \mathrm{m}$ & $93.5 \pm 17.2 \mu \mathrm{m}$ & $4.8 \pm 2.3 \mu \mathrm{m}$ & $51.8 \pm 8.2 \mu \mathrm{m}$ \\
\hline
\end{tabular}


By referring to the Schaeffler diagram [50] shown in Fig. 8 the structure of the HR3C evolved with the aluminising step at high temperature while that of In-800HT remained unchanged. The change in $\mathrm{HR} 3 \mathrm{C}$ could be related to the greater $\mathrm{Al}$ and $\mathrm{Cr}$ contents underneath the interface between the substrate and the coating that provokes an evolution from $100 \%$ austenite to $95 \%$ austenite $+5 \%$ ferrite. However, the XRD diffractogram obtained on this sample let not appear any ferrite phase probably because of unsufficient penetration of the X-rays to this interface. Therefore, the presence of the other minor phases besides austenite cannot be excluded.

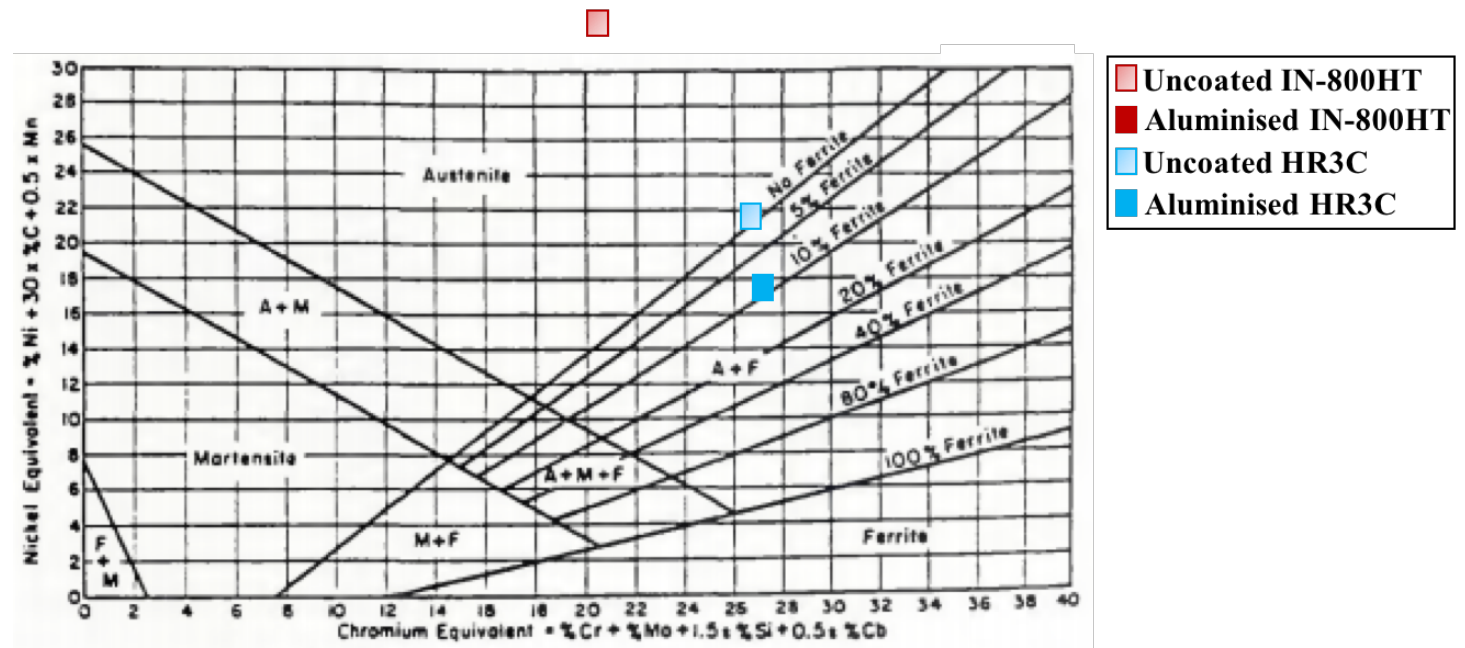

FIGURE 8. Schaeffler diagram [50]. Structures of uncoated/aluminised IN-800HT (red points) and HR3C (blue points).

For the P92 substrate, the untreated material (Fig. 7. c) exhibited a tempered martensitic structure, as reported by Bates et al. for Grade 91 ferritic-martensitic alloy [20]. $\mathrm{M}_{23} \mathrm{C}_{6}$ carbides characteristic of this type of alloy [51] were found in the P92 substrate as shown in Fig. 7. c). By referring to the CCT diagram for the P92 substrate (Fig. 9), it appeared that the structure of the steel was converted to austenite after the aluminisation carried out in this study. The annealing step also resulted in a 10-fold increase of grain size. 


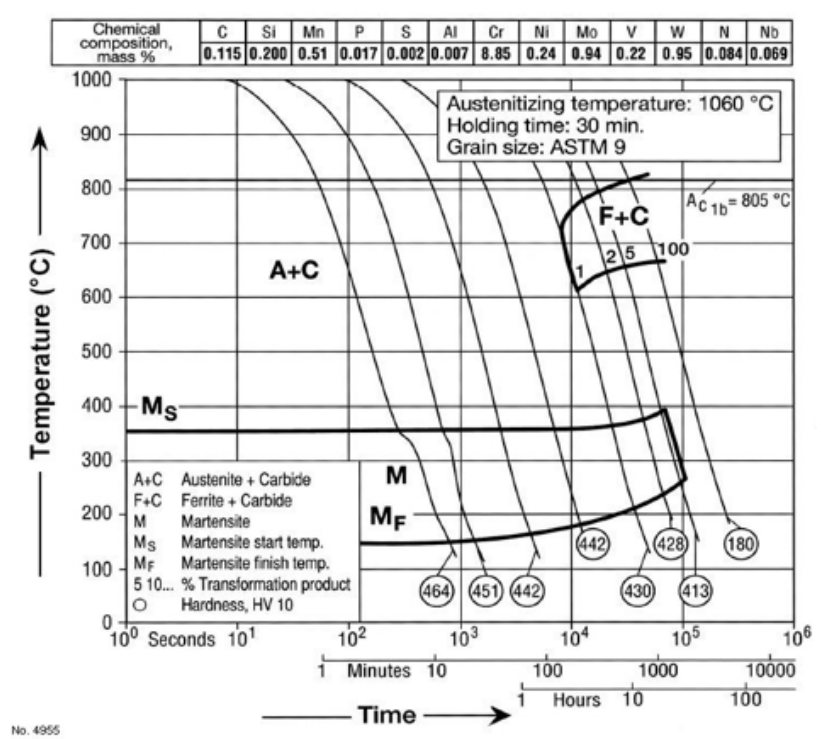

FIGURE 9. CCT diagram for P92 ferritic-martensitic steel [51].

\section{4-Microhardness}

Figure 10 summarizes the Vickers microhardness values measured before and after aluminisation. It appeared that the microhardness at the core of the ASS before aluminisation was higher compared to those obtained after aluminisation but the gap was negligible in view of the uncertainties of the measures. Before the annealing step, the microhardness of IN-800HT was $210.8 \pm 38.7 \mathrm{HV}$ whereas after aluminisation it was about 169.1 $\pm 11.7 \mathrm{HV}$ (Fig. 10. a). For the HR3C substrate (Fig. 10. b), the gap between the two values was smaller $(252.8 \pm 13.4$ and $235.8 \pm 13.6 \mathrm{HV}$ for, respectively, the uncoated and the aluminised specimens). On the contrary, the difference of Vickers microhardness between the aluminised (401.2 $\pm 26.3 \mathrm{HV})$ and the uncoated $(217.1 \pm 28.4 \mathrm{HV})$ P92 substrates was quite significant (Fig. 10. c).

The Vickers microhardness of the slurry aluminide coatings on IN-800HT, HR3C and P92 were also evaluated (Figs. 10). For the ASS, it appeared that the additive layers were harder than the interdiffusion zones and than the core of the substrates. In contrast, the opposite occurred in the aluminised P92 since the coating appeared softer than the core of the substrate (Fig. 10. c). 


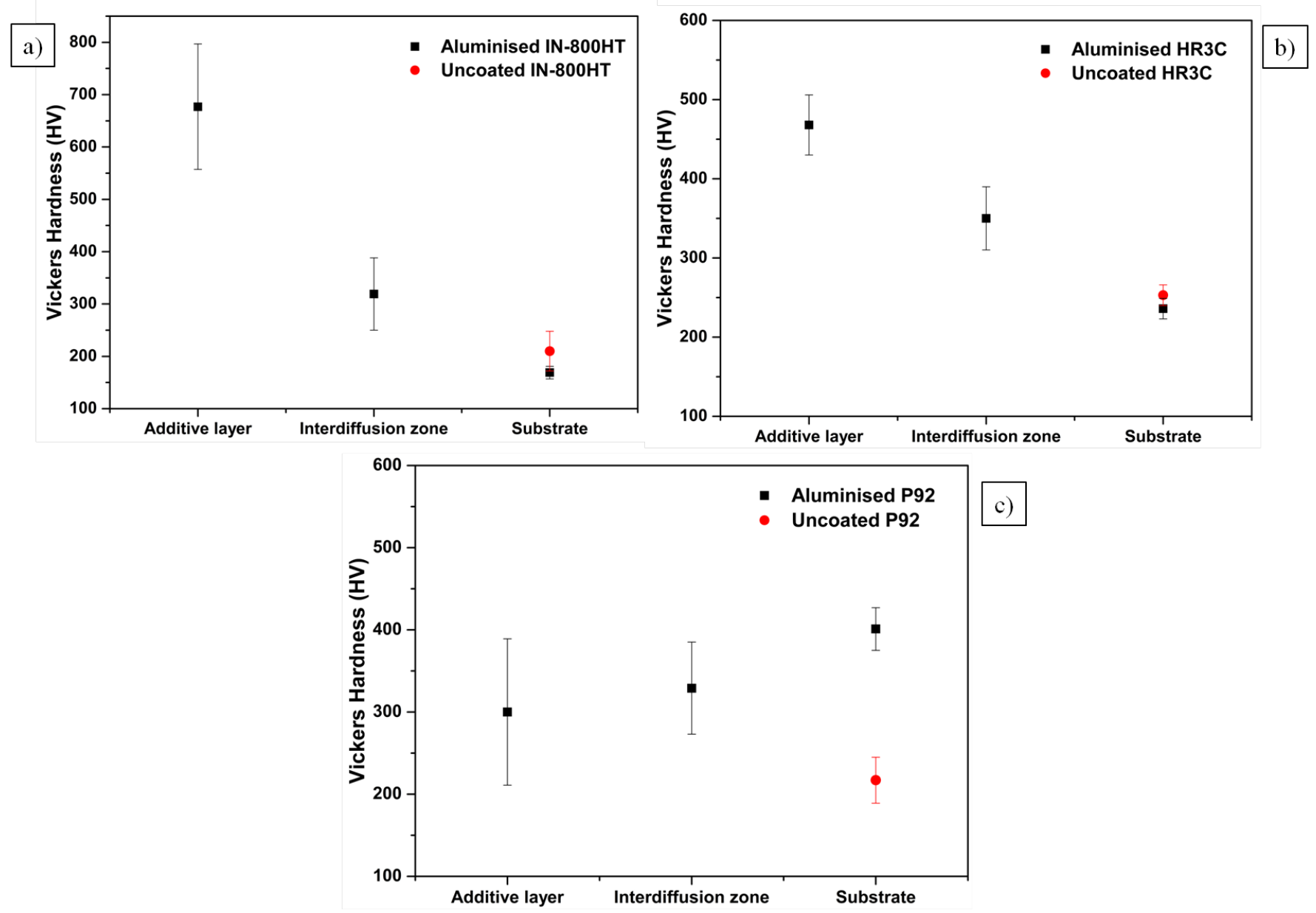

FIGURE 10. Vickers microhardness of uncoated and aluminised (a) IN-800HT, (b) HR3C and (c) P92 substrates.

\section{DISCUSSION}

\section{1 -Aluminium particles and corresponding slurry characterisation}

The DSC analyses carried out with the Al microparticles and the corresponding aluminium slurry allowed to confirm the choice of the thermal treatment conducted in this study. Indeed, with four phenomena taking place below $400^{\circ} \mathrm{C}$, the first ramp of the annealing has to be conducted slowly in order to achieve a gradual decomposition of the PVA. Then, a second heating rate up to $650^{\circ} \mathrm{C}$ followed by a $3 \mathrm{~h}$ dwell at this intermediate temperature involves the Al melting and the subsequent sintering of the particles. Also, the final dwell of the annealing has to be carried out at higher temperature in order to promote the $\mathrm{Al}$ inward and the simultaneous Ni, Fe outward diffusion to create the aluminide coating [23, 32]. The DSC 
measurements realized in this study confirm thus previous works realized in our group although the Al particles (supplier and size) were different [25-27, 29].

\section{2 - Aluminide coatings}

The IN-800HT, HR3C and P92 substrates were aluminised using the slurry analyzed in the first part of this study. The EDS profiles (Figs. 3. a) and b) and the X-ray patterns (Fig. 5. a) show that the additive layers elaborated on IN-800HT and HR3C are mostly composed by the B2(Fe, Ni)Al phase, which is indicative of inward Al diffusion into the steel matrix and, simultaneously, outward $\mathrm{Fe}$ and $\mathrm{Ni}$ diffusion. In both cases, the coatings appeared homogeneous in terms of thicknesses and composition. Although the thickness of the additive layers was the same, the interdiffusion zone of the HR3C substrate was thicker than the one on IN-800HT (respectively 49 and $19 \mu \mathrm{m}$ ). Previous works have related this phenomenon to the greater amount of $\mathrm{Cr}$ in the HR3C [25-29]. Indeed, during the aluminisation, $\mathrm{Cr}$ is incorporated in the Al coating, thus preventing the Al inward diffusion and the outward diffusion of the compounds contained in the substrate $[26,52]$. The Al distribution within the additive layers of the ASS appeared homogeneous whereas a $\mathrm{Cr}$ and $\mathrm{Fe}$ depletion was observed close to the additive/interdiffusion zones interface (Fig.6. a) and b). On the contrary a Ni enrichment was observed in these areas. $\mathrm{Cr}$ is known to have a very low solubility in Al-rich and stoichiometric aluminides thus explaining the presence of $\mathrm{Cr}$ in the absence of $\mathrm{Ni}$ and vice versa [53, 54]. Therefore, a significant increase of the $\mathrm{Cr}$ content was observed below the interface between the additive and the interdiffusion layers in both austenitic stainless steels. Moreover, in the HR3C steel, Cr-rich precipitates were highlighted in the interdiffusion zone and again, $\mathrm{Cr}$ was detected while $\mathrm{Ni}$ was not. Conversely, $\mathrm{Ni}$ was detected in the interdiffusion zone in the $\mathrm{Cr}$ poor areas. Carbides were also found within the interdiffusion zone of the IN-800HT substrate. Some elongated precipitates were observed in the HR3C case and were associated to AlN [28, $44,55,56]$.

Overall, the microstructure and the composition of the two coatings on the ASS are very close to those obtained on AISI 304 steel by chemical vapour deposition (CVD) in fluidised bed reactors $[33,57]$. However, the thermal treatments carried out $(\mathrm{Ar}(\mathrm{g}))$ in this work were shorter because of the combustion synthesis occurring between $\mathrm{Al}$ and the substrate, thus forming an aluminide, as described by Montero et al. [21] and Galetz and collab. [23]. Indeed, the melting 
of at least one of two components ( $\mathrm{Al}$ in this case) is a crucial step because it is the beginning of the intermetallics formation $[23,58]$. Previous studies have shown the high exothermic reaction occurring between $\mathrm{Fe}$ and $\mathrm{Al}$ in argon below the melting temperature of $\mathrm{Al}$ (i.e. $660^{\circ} \mathrm{C}$ ) $[21,59]$. Therefore, the intermediate step of the aluminisation is set at $650^{\circ} \mathrm{C}$, as also performed in [25-27]. A $3 \mathrm{~h}$ dwell at this temperature was sufficient because of the fast Al enrichment and the simultaneous Fe and Ni dissolution [23]. Such dissolution brings about the formation of the continuous diffusion layer shown in Figs. 3. a) and b). The cracks detected in the additive layers of the austenitic stainless steels were attributed to the difference existing between the different metallurgical phases. Indeed, when a gradient of thermal expansion coefficient exists between the coating and the substrate, the force generated can physically break the system [60]. However, these cracks do not propagate into the substrate, thus not jeopardizing the protection of the latter.

The aluminium diffusion coating elaborated on the ferritic-martensitic P92 steel was thicker than those obtained in the austenitic stainless steels. Nevertheless, the additive layer was also mostly composed by the B2-FeAl phase as highlighted by the EDS profiles (Fig. 3. c) and the X-ray patterns (Fig. 5. b). Needle-like precipitates were observed in the interdiffusion zone of the coated P92 and were attributed to AIN [20, 28, 45]. As reported by Agüero et al. [61, 62], these precipitates are due to the $\mathrm{N}$ content in the substrate $(0.046 \mathrm{wt} \%)$. Porosities were also detected at the coating/substrate interface and could be attributed to a Kirkendall effect due to the formation of chromium aluminides impeding locally further Al inward diffusion [54, 63]. Otherwise, Al was detected in the substrate until about $200 \mu \mathrm{m}$ from the coating surface to the substrate because the diffusion through a ferritic structure is relative fast [53,64]. No cracks were detected in the coated P92 because the gap between the substrate and the B2-FeAl phase is not probably significant enough.

\section{3 - Metallurgical evolutions induced by the aluminisation process}

A decrease of the grain size of the IN-800HT was noticed after aluminisation $(219.5 \pm 39.2 \mu \mathrm{m}$ and $134.2 \pm 11.7 \mu \mathrm{m}$, respectively for the uncoated and the aluminised substrate). In the HR3C case the evolution was less marked and the grain size was almost comparable. For the two austenitic stainless steels, the morphology observed after the thermal treatment (Figs. 7. a') and b') is typical of an austenitic structure [65]. Some square-like precipitates were found in the 
bulk of IN-800HT and the EDS analyses carried out let appeared high Ti and C contents and can be thus associated with $\mathrm{TiC}$ [45]. Moreover, some $\mathrm{Cr}$ carbides were detected and have been reported to confer high temperature strength to this alloy [11]. Segregation of $\mathrm{M}_{23} \mathrm{C}_{6}$ at the grain boundaries of the two steels was highlighted and is typical of the ASS after annealing at high temperatures $[9,13]$. Before aluminisation, these precipitates were revealed in the matrix.

By correlating EDS analyses and the Schaeffler diagram, it appeared that the composition underneath the interdiffusion zone/substrate interface did not evolve in the IN-800HT case. On the contrary, an evolution from the austenitic domain to $95 \%$ austenite $+5 \%$ ferrite was noticed in $\mathrm{HR} 3 \mathrm{C}$. $\mathrm{Al}$ and $\mathrm{Cr}$ are ferrite stabilizers and could thus result in a 5-10\% ferrite transformation in the substrate. Aluminisation through the ferritic phase is known to occur more readily than through the austenitic phase $[53,64]$. However, $\mathrm{Cr}$ is also a diffusion barrier for $\mathrm{Al}$ as $\mathrm{Cr}_{\mathrm{x}} \mathrm{Al} \mathrm{l}_{\mathrm{y}}$ intermetallic compounds block the inward Al diffusion [29]. Therefore, the greater $\mathrm{Cr}$ content in the interdiffusion zone blocked $\mathrm{Al}$ inward diffusion and the additive layer became thus more Al-rich in HR3C than in IN-800HT. Conversely, Fe diffused outwardly through the aluminide layers to stabilise at about $35 \mathrm{at} \%$ of the $\mathrm{B} 2-\mathrm{FeAl}$ phase according to the Al-Fe phase diagam of Fig. 4. b). Nevertheless, the compositions at the core of the IN800HT and the HR3C substrates are similar to those retrieved by EDS before aluminisation. It appears that the overall thickness of the Al-modified zone is negligible compared to the entire thickness of the system (coatings + substrates: about $2 \mathrm{~mm}$ ). Therefore, the cracks may appear because of the greater stiffness of the intermetallic compounds (in particular in the diffusion layer) than that of the substrate.

For the P92 substrate, the microstructure evolved in a larger extent during the aluminisation. Indeed, the initial tempered martensitic structure related by Bates et al. [20] converted to austenite one considering the CCT curves of Fig. 9. In order to recover the initial microstructure of this steel, after a rapid quench in air a subsequent annealing shall be performed at $760^{\circ} \mathrm{C}$ for 1 hour [66]. Nevertheless, the aluminisation realized in this study was done in a tubular furnace which is not able to cool down quickly. With our thermal treatment, the initial tempered martensitic structure converted -at least partly- to austenite when the samples were heated at $1050^{\circ} \mathrm{C}$ for 1 hour. Moreover, Wawszczak et al. [66] showed that the microstructure of a ferritic-martensitic steel (compositions close to those obtained for P92) does not change significantly after annealing at temperature below $400^{\circ} \mathrm{C}$. In this range of temperatures, the $\mathrm{Al}$ coating cannot be formed. The increase of the temperature allows the Al melting and, therefore the wet of the substrate allowing the start of the combustion synthesis process [21] which will 
enable the Fe enrichment of the coating. By increasing the temperature up to $1050^{\circ} \mathrm{C}$, the intermetallic phases created during the heating ramp become homogeneous to form and to maintain the $\mathrm{B} 2-\mathrm{FeAl}$ phase. Moreover, the relatively slow cooling rate to room temperature results in the precipiptation of $\mathrm{M}_{23} \mathrm{C}_{6}$ carbides that could have been partly dissolved and the martensitic microstructure recovered upon tempering at $760^{\circ} \mathrm{C}$ [51]. In contrast, quenching from the high coating temperature $\left(1000\right.$ or $\left.1050^{\circ} \mathrm{C}\right)$ may introduce mechanical failure of the coating through the ductile-to-brittle transition temperature (DBTT) [67]. The thermal treatment carried out in this study had an other consequence corresponding to the increase of the grain size. Indeed, it appeared that the grains were about 10 times bigger compared to those of the uncoated P92 samples. These observations are in agreement with the findings of Ellis et al. who have reported that the austenite grain size evolves as a function of the austenitization temperature; the higher the austenitization temperature and the bigger the grain size [67]. Such increase of the grain size during the heating of ferritic-martensitic has been also reported by Klueh and Shingledecker [68].

\section{4-Microhardness}

Generally speaking and within uncertainty of the measurements, the slurry aluminising process studied here seemed to soften slightly the matrix of the austenitic stainless steels. Nevertheless, a decrease in term of microhardness has also observed in [33] after a heat treatment due to the dissolution of carbides shown when comparing the microstructures of Fogs 7a) and 7b) (uncoated) with 7a') and 7b') (aluminised). For the P92 substrate, the evolution of the microhardness was non-negligible. Indeed, after aluminisation, the ferritic-martensitic steel appeared two times harder and a significant evolution of microstructure from a martensitic to an austenitic +carbides. As shown in Fig. 9 [51] and as reported by Hahn et al. [69], the P92 substrate should have been cooled sufficiently fast after the austenitization $\left(1050^{\circ} \mathrm{C}\right)$ and subsequently tempered. The significant change of the microstructure of the P92 material before and after the aluminisation explain the more pronounced microhardness evolution compared to the ASS.

The changes in composition and in microstructure also affected the Vickers microhardness of the slurry aluminide coatings elaborated on IN-800HT, HR3C and P92 (Fig. 10). For the ASS, it appeared that the additive layers were harder compared to the corresponding interdiffusion zone and substrate. The same trend has been reported for another austenitic steel (AISI 304) 
which was previously aluminised by CVD-FBR where comparable values of about $350 \mathrm{HV}$ were reported [33]. Moreover, the additive layer of IN-800HT was harder (700 HV) than that of HR3C (480HV). By comparing these results with the EDS profiles shown in Figs. 3, it appeared that the Ni content in the additive layer was higher for the IN-800HT (24 at\%) compared to the one noticed in the HR3C case (10 at\%). It is known that nickel accelerates the precipitation by diminishing the solubility of carbon [70] allowing an increase in term of microhardness $[13,71]$. In both cases, the microhardness noticed in the IDZ was smaller compared to those obtained in the additive layer, probably due to a Ni content decrease. The absence of $\mathrm{Ni}$ in the aluminide coating of P92 can thus also explain why the coating is much softer than that of the ASS substrates and of the P92 steel.

\section{CONCLUSIONS}

Slurry aluminide coatings were elaborated on IN-800HT and HR3C austenitic stainless steels and on P92 ferritic-martensitic steel. All the coatings were composed by an outer layer corresponding to the protective $\mathrm{B} 2-(\mathrm{Fe}, \mathrm{Ni}) \mathrm{Al}$ and $\mathrm{B} 2-\mathrm{FeAl}$ phase, for, respectively, the ASS and the ferritic-martensitic steel, and an inner interdiffusion layer. The thermal treatments of the three substrates were carried out in Ar and allowed the Al melting involving the combustion synthesis with the substrate. Thereby, the simultaneous $\mathrm{Al}$ inward diffusion in the steel matrix and the outward $\mathrm{Fe}$ (and $\mathrm{Ni}$ for the ASS) occurred forming a continuous and consistent diffusion layer mostly composed by B2.

The aluminisation of the ASS did not significantly change the grain size and the microhardness of the substrate whereas the thermal treatment had a non-negligible impact on the microstructure of the ferritic-martensitic substrate. Indeed, the initial tempered martensitic structure have been converted to austenite + carbides due to the absence of a final quench in air until $760^{\circ} \mathrm{C}$. Thus, the grain size appeared 10 times larger after the aluminisation process. The coated P92 specimens also assumed a large increase in term of microhardness because of the precipitation of $\mathrm{M}_{23} \mathrm{C}_{6}$ carbides along the grain boundaries during the annealing step.

\section{REFERENCES}

1. $\quad$ L. Zhao, H. Jing, L. Xu, J. An, G. Xiao, Materials and Design 34 (2012) 566

2. S. Khayatzadeh, D. W. J. Tanner, C. E. Truman, P. E. J. Flewitt, D. J. Smith, Engineering Fracture Mechanics 75 (2017) 57

3. B. He, L. Tian, J. Chen, X. Wang, Engineering Fracture Mechanics 171 (2017) 64 
4. K. Nicol, Status of advanced ultra-supercritical pulverized coal technology, IEA Clean Coal Centre, ISBN 978-92-9029-549-5 (2013)

5. B. Wang, Z.-D. Liu, S.-C. Cheng, C.-M. Liu, J.-Z. Wang, Journal of Iron and Steel Research, International 21(8) (2014) 765

6. J. Cao, Y. Gong, Z.-G. Yang, Materials Science and Engineering A 528 (2011) 6103

7. V. Sklenicka, K. Kucharova, M. Svoboda, L. Kloc, J. Bursik, A. Kroupa, Materials Characterization 51 (2003) 35

8. V. Sklenicka, K. Kucharova, M. Kvapilova, M. Svoboda, P. Kral, J. Dvorak, Materials Characterization 128 (2017) 238

9. S. Vujic, R. Sandström, C. Sommitsch, Materials at High Temperatures 32 (2015) 607

10. L. Y. Xu, P. Zhu, H. Y. Jing, K. Guo, S. X. Zhong, Y. D. Dan, Engineering Failure Analysis 31 (2013) 375

11. A. Akhiani, M. Nezakat, J. A. Szpunar, Materials Science Engineering: A 614 (2014) 250

12. M. Fulger, M. Mihalache, D. Ohai, S. Fulger, S. C. Valeca, Journal of Nuclear Materials 415 (2011) 147

13. Z. Zhang, Z. Hu, H. Tu, S. Schmauder, G. Wu, Materials Science and Engineering A $681(2017) 74$

14. S. Khayatzadeh, D. W. J. Tanner, C. E. Truman, P. E. J. Flewitt, D. J. Smith, Engineering Fracture Mechanics 75 (2017) 57

15. L. Zhao, H. Jing, L. Xu, J. An, G. Xiao, Materials and Design 34 (2012) 566

16. T. Sakthivel, M. Vasudevan, K. Lahan, P. Parameswaran, K.S. Chandravathi, S. Panneer Selvi, V. Maduraimuthu, M.D. Mathew, Materials Science and Engineering A 591 (2014) 111

17. N. Saini, C. Pandey, M. M. Mahapatra, Materials Science and Engineering A 668 (2017) 250

18. Z. D. Xiang, S. R. Rose, P. K. Datta, Intermetallics 17(6) (2009) 387

19. E.J. Opila, N.S. Jacobson, D.L. Myers, E.H. Copland, JOM 58, 22 (2006)

20. B. L. Bates, Y. Zhang, S. Dryepondt, B. A. Pint, Surface and Coatings Technology 240 (2014) 32

21. X. Montero, I. Demler, V. Kuznetsov, M. C. Galetz, Surface and Coatings Technology 309 (2017) 179

22. A. Agüero, J. C. del Hoyo, J. Garcia de Blas, M. Garcia, M. Guttierez, L. Madueno, S. Ulargui, Surface and Coatings Technology 213 (2012) 229 
23. M. C. Galetz, X. Montero, M. Mollard, M. Günthner, F. Pedraza, M. Schütze, Intermetallics 44 (2014) 8

24. X. Montero, M. Galetz, M. Schütze, JOM 67(1) (2015) 77

25. F. Pedraza, M. Proy, C. Boulesteix, P. Krukovskyi, M. Metel, Materials and Corrosion 67 (2016) 1059

26. C. Boulesteix, F. Pedraza, M. Proy, I. Lasanta, T. de Miguel, A. Illana, F. J. Perez, Oxidation of Metals 87 (2017) 469

27. F. Pedraza, C. Boulesteix, M. Proy, I. Lasanta, T. de Miguel, A. Illana, F. J. Pérez, Oxidation of Metals 87 (2017) 443

28. A. Agüero, R. Muelas, M. Gutiérrez, R. Van Vulpen, S. Osgerby, J. P. Banks, Surface and Coatings Technology 201(14) (2007) 6253

29. C. Boulesteix, B. Grégoire, F. Pedraza, Surface \& Coatings Technology 326 (2017) 224

30. C. Boulesteix, F. Pedraza, Surface \& Coatings Technology 327 (2017) 9

31. B. Rannou, F. Velasco, S. Guzman, V. Kolarik, F. Pedraza, Materials Chemistry and Physics 134 (2012) 360

32. M. Mollard, F. Pedraza, B. Bouchaud, X. Montero M. C. Galetz, M. Schütze, Surface and Coatings Technology 270 (2015) 102

33. F. J. Pérez, F. Pedraza, M. P. Hierro, P. Y. Hou, Surface and Coatings Technology 133134 (2000) 338

34. A. A. Fasching, G. R. Edwards, S. A. David, Scripta Metallurgica et Materialia 30(8) (1994) 1003

35. M. Mollard, $\mathrm{PhD}$ thesis "Elaboration de systèmes barrière thermique par barbotine. Comportement du nickel et de ses superalliages revêtus en oxidation cyclique à haute température", University of La Rochelle (2012) (in French)

36. B. Rannou, $\mathrm{PhD}$ thesis "Slurry coatings from aluminium microparticles on Ni-based superalloys for high temperature oxidation protection", University of La Rochelle (2012) (in English)

37. H. Okamoto, Journal of Phase Equilibria and Diffusion 29 (2008) 112

38. D. Webster, Journal de Physique 48(C3) (1987) 685

39. Physical Metallurgy and Processes, Handbook of Aluminum, Volume 1, edited by G. E. Totten, D. Scott MacKenzie, New York (2003) 37

40. X. Montero, M. C. Galetz, M. Schütze, Surface and Coatings Technology 206(7) (2011) 1586

41. L. Eleno, K. Frisk, A. Schneider, Intermetallics 14 (2006) 1276 
42. ASM Handbook, "Alloy Phase Diagrams” Vol. 3 (1992) Ohio 2.44

43. R. Viswanathan, Advanced Materials and Processes 162 (2004) 73

44. A. Agüero, V. Gonzalez, M. Guttierrez, R. Knödler, R. Muelas, S. Straub, Materials and Corrosion 62 (2011) 561

45. A. Agüero, M. Hernandez, A. Santaballa, Oxidation of Metals 79 (2013) 601

46. K. Wang, Z. Gui, P. Liu, Y. Wang, Y. Zhang, Procedia Engineering 81 (2014) 1713

47. L. Xie, D. Chen, E. H. Jordan, A. Ozturk, F. Wu, X. Ma, B. M. Cetegen, M. Gell, Surface and Coatings Technology 201 (2006) 1058

48. L. A. Spyrou, P. I. Sarafoglou, N. Aravas, G. N. Haidemenopoulos, Engineering Failure Analysis 45 (2014) 456

49. Y. Zhou, Y. Liu, X. Zhou, C. Liu, J. Yu, Y. Huang, H. Li, W. Li, Journal of Materials Science and Technology, DOI: 10.1016/j.jmst.2017.01.025 (2017)

50. D. J. Kotecki, T. A. Siewert, Welding Research Supplement (1992) 171

51. B. Hahn, W. Bendick, Vallourec report "Pipe steels for modern high-output power plants" (2015)

52. W. J. Cheng, C. J. Wang, Applied Surface Science 277 (2013) 139

53. F. Pedraza, C. Gomez, M. C. Carpintero, M. P. Hierro, F. J. Pérez, Surface and Coatings Technology 190 (2005) 223

54. A. J. Rasmussen, A. Agüero, M. Gutierrez, M. J. Ostergard, Surface and Coatings Technology 202(8) (2008) 1479

55. P. Berthod, S. Michon, S. Mathieu, R. Podor, C. Rapin, P. Steinmetz, Materials Science Forum 461-464, 1117 (2004)

56. T. Sourmail, Materials Science and Technology 17, 1 (2001); W.E. White, I. Le May, Metallography 5, 333 (1972)

57. F. J. Pérez, M. P. Hierro, F. Pedraza, M. C. Carpintero, C. Gomez, R. Tarin, Surface and Coatings Technology 145(1-3) (2001) 1

58. J. J. Moore, H. J. Feng, Progress in Materials Science 39 (1995) 275

59. H. Gao, Y. He, P. Shen, J. Zou, N. Xu, Y. Jiang, B. Huang, C. T. Liu, Intermtallics 17 (2009) 1041

60. K. Nicol, "High temperature steels in pulverised coal technology". IEA Clean Coal Centre (2014) 40

61. A. Agüero, R. Muelas, A. Pastor, S. Osgerby, Surface and Coatings Technology 200 (2005) 1219

62. A. Agüero, R. Muelas, Materials Science Forum 461-464 (2004) 957 
63. P. Moretto, J. Bressers, D. J. Arrell, Materials Science and Engineering A 272 (1999) 310

64. L. Levin, A. Ginzburg, L. Klinger, T. Werber, A. Katsman, P. Schaaf, Surface and Coatings Technology 106 (1998) 209

65. R. Dehmolaei, M. Shamanian, A. Kermanpur, Materials Characterization 60(3) (2009) 246

66. R. Wawszczak, A. Baczmanski, M. Marciszko, M. Wrobel, T. Czeppe, K. Sztwiertnia, C. Braham, K. Berent, Materials Characterization 112 (2016) 238

67. P. J. Ennis, A. Czyrska-Filemonowicz, Shadana 28 (2003) 709

68. R. L. Klueh, J. P. Shingledecker, Report: "Investigation of a modified 9Cr-1Mo (P91) (2006)

69. B. Hahn, V. Baumhoff, M. Zschau, “Advanced Heat Resistant Steels for Power Generation” in Book - Institute of Materials 708 (1998) 157

70. M. F. Mc Guire, ASM International, Stainless Steels for Desing Engineers (2008) 69

71. R. Dehmolaei, M. Shamanian, A. Kermanpur, Materials Characterization 60(3) (2009) 246 